\title{
Pain and microcrystalline arthritis
}

\author{
R. Ramonda, P. Frallonardo, F. Oliviero, M.G. Lorenzin, A. Ortolan, \\ A. Scanu, L. Punzi \\ Rheumatology Unit, Department of Medicine-DIMED, Padua University, Italy
}

\begin{abstract}
SUMMARY
Microcrystals are responsible for some of the most common and complex arthropathies which are often accompanied by intense, severe pain and inflammatory reactions. The main pathogens are crystals of monosodium urate (MSU), responsible for the gout, calcium pyrophosphate (CPP), which deposits also in various clinical forms of arthopathies, and basic calcium phosphate associated with osteoarthritis.

In this context, the microcrystal arthritis is characterized by multiple, acute attacks followed by chronic pain, disability, impaired quality of life, and increased mortality. Given their chronic nature, they represent an ever more urgent public health problem. MSU and CPP crystals are also able to activate nociceptors. The pain in mycrocrystalline arthritis (MCA) is an expression of the inflammatory process. In the course of these diseases there is an abundant release of inflammatory molecules, including prostaglandins 2 and kinins. Interleukin-1 represents the most important cytokine released during the crystal-induced inflammatory process.

Therefore, clinically, pain is the most important component of MCA, which lead to functional impairment and disability in a large proportion of the population. It is fundamental to diagnose these diseases as early as possible, and to this aim, to identify appropriate and specific targets for a timely therapeutic intervention.
\end{abstract}

Key words: Microcrystal arthritis, Urate crystal, Calcium pyrophosphate crystal, Basic phospate crystal, Prostaglandin interleukin-1, Pain, Joint inflammation.

Reumatismo, 2014; 66 (1): 48-56

\section{BACKGROUND}

Mising icrocrystals are responsible for some of the most common and complex arthropathies, which are often accompanied by intense, severe pain and inflammatory reactions (1-3).

The main pathogens are crystals of monosodium urate (MSU), responsible for gout, calcium pyrophosphate (CPP), which deposits also in various clinical forms of arthopathies and basic calcium phosphate (BCP) associated to osteoarthritis (OA). The examination of the synovial fluid (SF) of affected patients makes it possible to identify the various types of crystals involved $(4,5)$.

In all of its forms, mycrocrystalline arthritis (MCA) is the inflammatory arthropathy with the highest prevalence in the population at large.

Roberta

Rheumatology Unit

Department of Medicine-DIMED

Padua University

Via Giustiniani 2 - 35128 Padua, Italy

E-mail: roberta.ramonda@unipd.it
Gout, in particular, is the most common arthritis in males over 40 years of age and the most prevalent inflammatory arthritis, affecting 1/4 of adults in Europe (6). Its prevalence in Italy ranges between 0.45 and $0.90 \%$, and, like in other developed countries, its incidence is increasing (7). Acute CPP crystal arthritis is the most common acute monoarthritis in the elderly with a prevalence of $10 \%(8,9)$.

Heath-related quality of life (QoL) in patients with MCA may be adversely affected by severe or chronic pain, associated to comorbidities, such as renal and cardiovascular diseases, the metabolic syndrome, OA, and suboptimal management often due to misdiagnosis (10).

In this context, these conditions characterized by multiple, acute attacks followed by chronic pain, disability, impaired QoL, and increased mortality, are becoming an ever more urgent public health problem (11-14).

Some studies have reported that body pain, physical function, emotional state, and general health, are worse in MCA patients than in age-matched healthy controls (15). 


\section{CLINICAL ASPECTS OF MYCROCRYSTALLINE ARTHRITIS}

Gout is a condition in which there is an excess amount of uric acid (hyperuricemia above $390 \mu \mathrm{mol} / \mathrm{L}$ or $6.5 \mathrm{mg} / \mathrm{dL}$ ), leading to the formation of MSU in various tissues. A typical attack is characterized by an abrupt onset and acute, violent, worsening pain that lasts a few days and generally subsides on its own without medication (16). Gout is traditionally classified on the basis of the characteristics in the various phases of the disease. Its stages are classified as: asymptomatic hyperuricemia, acute gout, intercritical gout, chronic gout and/or tophaceous gout, urate nephropathy with systemic involvement (14).

The first manifestation of gout is typically an acute episode of monoarticular arthritis of the metatarsophalangeal joint of the large toe (podagra) which is often very painful, characterized by a rapid and violent onset, often at night. The pain is accompanied by all the signs of an acute inflammation (redness, heat, swelling, pain and loss of function). The episode generally tends to resolve itself on its own without any medication. Almost $90 \%$ of the patients who have suffered a gout attack experience other episodes over the next 5 years (17).

Atypical manifestations may present over the course of the disease; and at times other joints (e.g., finger joints) may be affected in oligoarticular or polyarticular forms of arthritis. Moreover, MSU crystals can, in fact, be found in the SF of asymptomatic patients even during the intercritical phase (18). The disease's natural history as far as gout is concerned is characterized by an increased number of flares and a reduction in asymptomatic periods between attacks. The severity of gout is defined by the number of acute attacks. In particular, severe gout is characterized by three or more flares in the previous year and the presence of tophi (3). Patients with these characteristics have pain and scores of the health utility (SF36) index that are similar to those of patients with rheumatoid arthritis (RA) or systemic lupus (19). Gout severity is

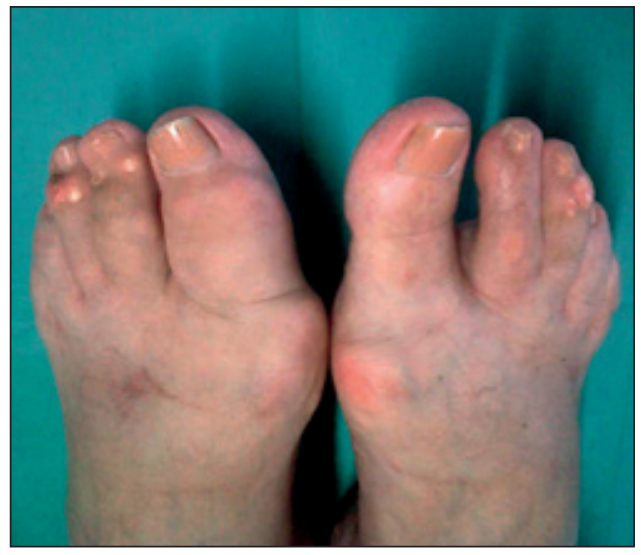

Figure 1 - Poliarticular gout in women.

also defined by an increased utilization of primary care clinics (20). It is particularly difficult to make a differential diagnosis of the polyarticular form as opposed to other classic forms such as RA or psoriatic arthritis (PsA), as in the past it was attributed to the chronic phase but it is now more often associated with the onset of the disease, particularly in women. In the polyarticular form, pain is in fact prevalently located in the hands and feet often as an early manifestation of the disease (21) (Fig. 1).

These patients present a peculiar kind of pain and symptoms characterized by recurrent, acute attacks and at times a simultaneous involvement of the small joints that are difficult to classify (21). When its onset occurs in old age, gout is a particularly complex disease with significant clinical and epidemiological differences with respect to the classic adult form. There can be an insidious subacute or acute onset, with fewer inflammatory signs, but frequently with polyarticular involvement often of hand joints and at times simultaneously of the large joints. The presence of tophi in joints affected by OA can complicate even further the diagnosis. The higher prevalence among the female sex, frequent impairment in kidney function and/or the use of drugs such as diuretics which reduce urate excretion are all predisposing factors for a chronic form and make the disease more difficult to recognize and treat it (16) (Fig. 2).

All joints can be involved in microcrystalline arthritis and, as a curiosity, an acute 


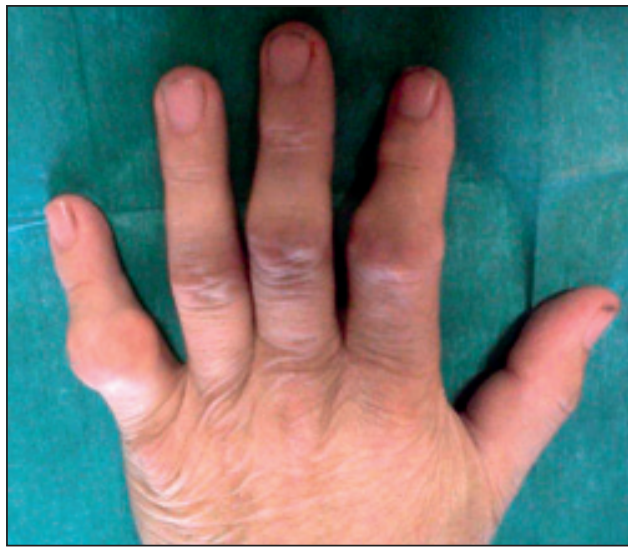

Figure 2 - Poliarticular gout in elderly.

vertebral pain accompanied by neurological signs, paresthesia, and at times paraplegia could be an expression of spinal involvement. MSU or CPP depositions may be detected and can lead to a compression of the spinal cord and/or nerve roots with impairment of the neurological system $(22,23)$.

We recently reported the finding of MSU and CPP crystals that were simultaneously

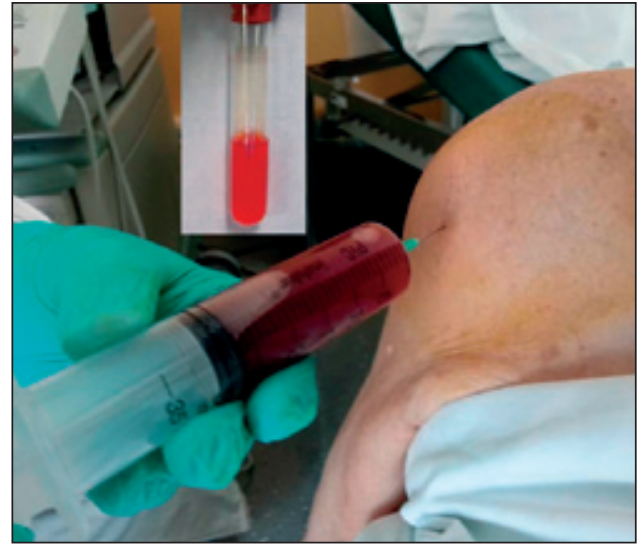

Figure 3 - Milwaukee shoulder and synovial fluid.

detected in the synovial fluid in some of our patients with joint diseases, associated, in some cases, to other joint conditions $(18,24)$. CPP crystals were found more frequently with respect to MSU crystals; the highest prevalence was found in OA patients, followed by RA, and then by PsA patients $(18,24)$. The OA patients with positivity to CPP crystals in their SF usually had a longer disease course (23-27). The

Table I - Clinical diagnostic aspects of mycrocrystalline arthritis.

\begin{tabular}{|l|l|l|l|l|}
\hline Features & MSU & CPP & BCP \\
\hline Onset & & Abrupt, rapid, worsening & Abrupt, rapid develop & Abrupt \\
\hline Gender & & $>$ male adult & Female & Female \\
\hline Age (years) & & $40-50$ & $>65$ & $\sim 40$ \\
\hline \multirow{4}{*}{ Symptoms } & Pain & Violent, severe, worsening & Severe & Severe \\
\cline { 2 - 5 } & Swelling & Soft tissue & Soft tissue & Soft tissue, bursae \\
\cline { 2 - 5 } & Loss of function & Frequent, disabling & Frequent, disabling & Frequent, disabling \\
\cline { 2 - 5 } & Fever & Frequent with shivering & Common & Possible \\
\hline \multirow{4}{*}{ Signs } & Tenderness & Persistent & Persistent & Persistent \\
\cline { 2 - 5 } & Redness & Intense & Intense & Mild to moderate \\
\cline { 2 - 5 } & Warmth & Intense & Intense & Mild to moderate \\
\hline Timing & $\begin{array}{l}\text { Nighttime, seasonal (spring, } \\
\text { autumn), dehydration }\end{array}$ & None & Variable \\
\hline Resolution & 1 week & $1-3$ weeks & Slowly \\
\hline \multirow{4}{*}{$\begin{array}{l}\text { Muscloskeletal } \\
\text { involvement }\end{array}$} & Poliarticular & Women and elderly & Frequent & Shoulder, knee \\
\cline { 2 - 5 } & Rare & $\begin{array}{l}\text { axial joints, tendons, } \\
\text { Poliarticular }\end{array}$ & $\begin{array}{l}\text { C1-C2* (crowned tooth } \\
\text { syndrome) } \\
\text { Poliarticular, bursitis }\end{array}$ & Polyarticular \\
\hline Other tissues & & Possible & Rare & Rare \\
\hline
\end{tabular}

MSU, monosodium urate; CPP, calcium pyrophosphate; BCP, basic calcium phosphate. 
RA patients with CPP crystals in their SL also had a longer disease course and were older $(28,29)$.

$\mathrm{BCP}$ crystals are more frequent in $\mathrm{OA} \mathrm{SF}$, even in the early stage of the disease. Many studies are presently investigating their precise role in the pathophysiology of the pain experienced by these patients. The presence of BCP crystals in OA SF denotes a more serious form of the disease with chronic pain and frequent disability (30).

The differential diagnosis of an acute gout attack is made against other forms of MCA, such as CPP-related pseudogout/ chondrocalcinosis or BCP-related disease, whose clinical features are similar to those presenting during an acute gout attack. It is to be remembered, in particular, that the Milwaukee shoulder syndrome (apatiteassociated destructive arthritis), is associated with periarticular or intraarticular deposition of hydroxyapatite crystals. This precipitates an acute, rapid decline in joint function and degradation of joint anatomy. The disruption of the rotator cuff generally follows and there is extensive damage to the cartilage and the subcondral bone, at times affecting the knee (Fig. 3).

CPP deposition, which is frequent in elderly women, presents typical signs of OA, such as mechanical pain, bone swelling, crepitus, moderate stiffness, and various degrees of synovitis. The knee is the joint that is prevalently involved. A chronic form of BCP deposition can be associated with all symptoms linked to OA.

The clinical aspects of mycrocrystalline arthritis are presented in Table I.

\section{PATHOPHYSIOLOGICAL MECHANISMS OF JOINT PAIN IN MICROCRYSTALLINE ARTHRITIS}

Various factors may be involved in the pain/ inflammatory process in MCA. In particular, the inflammatory response of MCA is characterized by a cellular infiltrate rich in neutrophils and the production of proinflammatory cytokines as well as other inflammatory mediators. Indeed, a massive influx of leukocytes, mainly neutrophils, and high levels of cytokines have been detected in SF of patients with gout (31). A key role in the inflammatory process has been attributed to NLRP3 inflammasome, a cytoplasmic complex which cleaves pro-interleukin (IL)-1 $\beta$ to the active secreted product $(2,3)$. The inflammasome is formed by a member of the NALP protein family and the adaptor protein ASC that connects the NALPs with caspase-1. MSU and CPP crystals are also able to activate nociceptors. Some have suggested that nociceptor stimulation is not induced directly by the crystals themselves but, could, instead, be linked to pro-nociceptive mediators released after crystal phagocytosis by the leukocytes (32). It has, nevertheless, been demonstrated that crystals alone can trigger joint pain without leukocyte recruitment (33), thus suggesting that even resident cells, like mast cells, can contribute to pain development (34).

\section{Transient receptor potential}

Transient receptor potential (TRP) ion channels seem to play a role in nociceptive pain induced by crystals, and in particular the transient receptor potential vanilloid 1 (TRPV1) appears mainly involved. TRPV1 receptor is a non-selective cation channel that is activated by several stimuli, such as heat, acidic conditions, or by capsaicin. Indeed, in vivo experiments have demonstrated that an injection of selective TRPV1 receptor antagonists into the paw of rats and perineural capsaicin desensitization significantly reduced MSU-induced nociception and edema (34). An increased immunoreactivity of the TRPV1 receptor has, moreover, been observed in rat joint tissue after MSU crystal injection (35). TRPV1 has been localized in the small-diameter $\mathrm{C}$-fibers and in the medium-diameter $\mathrm{A} \delta$ fibers (36). Studies on the physiological properties of similar fibers in the ankle joints of chickens rendered arthritic by sodium urate injection indicated that there is an increased sensitivity in the C-fibers, but not in the A $\delta$ ones (37).

More recently, another TRP, the TRP ankyrin 1 (TRPA1), was shown to play a 
key role in MSU-induced nociception and edema (38). TRPA1 receptor is usually coexpressed with TRPV1 in a sub-type of primary afferent fibers and demonstrated a synergistic effect in different pain conditions (39-41). Using a rodent model of MSU-crystal induced inflammation, Trevisan et al. demonstrated that TRPA1 is responsible for the MSU crystal-induced cold allodynia and that its activation is concomitant to increased levels of reactive oxygen species, in particular $\mathrm{H}_{2} \mathrm{O}_{2}$, in the injected tissue. These results suggest that oxidative stress evoked by the crystals may be involved in pain development (38). As stated above, nociceptive pain is mediated by several inflammatory mediators induced by the interaction of pathogenic crystals with all synovial cell types, including neutrophils, fibroblasts, and monocytes/macrophages (3). The most important of these molecules involved in joint pain are IL-1B, prostaglandin (PG) E2, bradykinin, and substance $\mathrm{P}$.

\section{Prostaglandins}

PGE2 is considered to be the major contributor to inflammatory pain in arthritic conditions. Its production derives from the hydrolysis of arachidonic acid by cyclooxygenases (COX) and cytosolic and microsomal PGE synthases. PGE2 exerts its effects via a variety of $\mathrm{E}$ prostanoid (EP) receptors (mainly EP1 and EP4), which are present in both the peripheral sensory neurons and the spinal cord (39). EP1 and EP4 stimulation lead to the activation of protein kinase $\mathrm{C}$ (PKC) and PKA, respectively, in peripheral nociceptors (42). PKC and PKA activate multiple molecules including TRPV1 channels, purinergic P2X3 receptors, calcium channels, as well as voltagegated sodium channels leading to inflammatory hyperalgesia.

It has been found that inflammatory MSU crystals are able to stimulate de novo synthesis of COX-2 in human monocytes through tyrosine phosphorylation, leading to the transcription of PGE2 which, in addition to its pain-triggering role, may participate in several ways to the symptoms that are marks of gouty arthritic flares, such as early vasodilation, edema, and leukocyte migration (43). IL-1 $\beta$ has, moreover, been shown to enhance the expression of COX-2 and microsomal PGE synthase-1 at the mRNA and protein levels, in particular in the presence of bradykinin (44). Prostanoids have, in fact, been shown to increase the sensitivity of sensory neurons to bradykinin in various models (45).

\section{The kinin system}

In addition to the classic and alternative complement pathway, MSU crystals also activate Hageman factor and the contact system of coagulation, leading to the generation of kallicrein, bradykinin, plasmin, and other inflammatory mediators (46). Bradykinin is one of the most potent painproducing agents formed under inflammatory conditions, and a multitude of its excitatory and sensitizing effects on peripheral nociceptors have been described. Its levels have been shown to be affected, at least in part, by prostanoids, as the non-steroidal anti-inflammatory drugs flurbiprofen (a nonselective COX inhibitor) reduces bradykinin at the inflammation site (47) suggesting that there are mutual interactions between products of the arachidonic acid-cyclooxygenase cascade and the kinin system in pain mediation.

The effects of bradykinin are mediated by $\mathrm{B} 1$ and $\mathrm{B} 2$ receptors whose expression is enhanced by pro-inflammatory cytokines such as IL- $1 \beta$ and tumor necrosis factor- $\alpha$ (TNF- $\alpha$ ). Through the activation of phospholipase $\mathrm{C}$ and $\mathrm{A} 2$, these receptors may contribute to the development of pain and hyperalgesia not only in the periphery but also in the spinal cord (48). It has been hypothesized that at the beginning of the inflammatory process kinins exert their actions predominantly through the constitutive activation of $\mathrm{B} 2$ receptors, while B1 receptors may play an important role in persistent inflammatory pain that is reflected in the antinociceptive activity of B1 receptor antagonists (45). Recently, some Authors demonstrated that B2 receptors play a role in maintaining MSU crystal-induced leukocyte infiltration and membrane permeability and identified B2 receptors as 
a potential therapeutic target for managing inflammation in gout (49).

\section{Substance P}

Stimulation of C-fibers and activation of TRPV1 and TRPA1 receptors can result in the release of substance $P$, a neurotransmitter which is involved in the transmission of pain impulses from the peripheral receptors to the central nervous system, but which also has pro-inflammatory effects by promoting plasma extravasation, leucocyte recruitment, and mast cell degranulation and producing prostaglandins and cytokines, such as TNF, IL-6 and IL-1 (50). The main substance P-receptor, neurokinin-1 (NK1), has been reported to be expressed in the synovial tissue of patients with rheumatoid arthritis (51) and higher levels of substance $\mathrm{P}$ have been observed in the synovial fluid of patients with inflammatory arthritis (52). It has been experimentally demonstrated that acute urate arthritis induced in the ankle joint of chicks produces a neurogenic depletion of substance $\mathrm{P}$ from the peripheral nerve fibers in the synovial and subsynovial tissues (53) and that a blockade of NK1 receptors reduces MSU crystal-induced nociception and edema (54).

\section{Interleukin-1 $\beta$}

IL-1 $\beta$ production, via activation of the NALP3 inflammasome, is the hallmark of crystal deposition diseases (54). Since IL-1 $\beta$ plays a critical role in different pain states contributing in inducing and maintaining pain in both peripheral and central nervous system, an upregulation of this cytokine may also be involved in the pain associated with crystal-induced arthritis.

The release of IL- $1 \beta$ may contribute to nociceptive responses through indirect mechanisms leading to the release and/or activation of other nociceptive molecules, including nerve growth factor, prostaglandin, IL-6, substance P, and MMP9 (55-59). A direct action of IL-1 $\beta$ on nociceptors has, nevertheless, also been observed. Indeed, there is evidence that IL-1 receptor type I (IL-1R1) is expressed in sensory neurons and that IL- $1 \beta$ modulates neuronal excitability by involving neuronal receptors, including TRPV1, sodium channels, GABA and NMDA receptors (60-62).

Blockade of IL-1 $\beta$ activity, for example, using the IL-1 receptor antagonist (IL$1 \mathrm{Ra}$, anakinra), has been shown to be an effective treatment for the inflammatory symptoms of crystal-induced arthritis, including pain. It has been reported, in agreement with this finding, that pain in gouty patients treated with anakinra decreased by $79 \%$ within less than three days (63). Other investigators have reported, moreover, that systemic IL-1 inhibition, using IL1R1 knockouts or mIL1 Trap (a murine IL-1 $\beta$ blocking agent), prevented and suppressed ankle hyperalgesia and synovitis in a mouse model of gouty arthritis (64). According to a recent study, anakinra treatment provided good joint pain relief in patients affected by CPP crystal-induced arthritis (65).

The main mediators involved in the development of pain in MCA are presented in Table II.

\section{CONCLUSIONS}

The pain in MCA is an expression of the inflammatory process. In the course of these diseases, indeed, there is an abundant release of inflammatory molecules, including PGE2 and kinins, directly involved in

Table II - Main mediators involved in the development of pain in mycrocrystalline arthritis.

\begin{tabular}{|l|l|l|}
\hline Mediators & Main sources & Main mechanism of action \\
\hline PGE2 & Monocytes, neutrophils, fibroblasts & Stimulation of nociceptors through EP1-EP4 receptors \\
\hline Kinins & Plasma & Stimulation of nociceptors through B1-B2 receptors \\
\hline IL-1B & Monocytes & $\begin{array}{l}\text { Stimulation of nociceptors; release and/or activation of } \\
\text { nociceptive molecules }\end{array}$ \\
\hline Substance P & Neurons, inflammatory cells & Stimulation of NK1 receptor \\
\hline
\end{tabular}

PGE2, prostaglandin E2; EP, prostaglandin receptor; B, bradykinin receptor; IL-1, interleukin-1; NK1: neurokinin-1 receptor. 
the development of pain by stimulation of nociceptors. IL-1, which represents the most important cytokine released during the crystal-induced inflammatory process, is also implicated in pain at both peripheral and central level. In fact, although there is no data in the literature regarding MCA, it is conceivable that IL- 1 contributes to nociceptive responses through indirect mechanisms, such as the release and the activation of other nociceptive molecules including PGE2 and substance P. Clinically, pain is the most important component of MCA which lead to functional impairment and disability in a large proportion of the population. It is important to diagnose as early as possible these diseases, and to this aim, to identify appropriate and specific targets for a timely therapeutic intervention.

\section{REFERENCES}

1. So A. New knowledge on the pathophysiology and therapy of gout. Z Rheumatol. 2007; 66: 562-7.

2. Busso N, So A. Mechanisms of inflammation in gout. Arthritis Res Ther. 2010; 12: 206.

3. Punzi L, Scanu A, Ramonda R, Oliviero F Gout as autoinflammatory disease: new mechanisms for more appropriated treatment targets. Autoimmun Rev. 2012; 12: 66-71.

4. Pascual E, Jovaní V. Synovial fluid analysis. Best Pract Res Clin Rheumatol. 2005; 19: 371-86.

5. Schumacher HR, Reginato AJ. Atlas of synovial fluid analysis and crystal identification. Philadelphia: Lea and Febiger. 1991.

6. Annemans L, Spaepen E, Gaskin M, Bonnemaire M, Malier V, Gilbert T, et al. Gout in the UK and Germany: prevalence, comorbidities and management in general practice 20002005. Ann Rheum Dis. 2008; 67: 960-6.

7. Trifiro G, Morabito P, Cavagna L, Ferrajolo C, Pecchioli S, Simonetti M, et al. Epidemiology of gout and hyperuricaemia in Italy during the years 2005-2009: a nationwide population-based study. Ann Rheum Dis. 2012; 72: 694-700.

8. Ramonda R, Musacchio E, Perissinotto E, Sartori L, Punzi L, Corti MC, et al. Prevalence of chondrocalcinosis in Italian subjects from northeastern Italy. The Pro. V. A. (PROgetto Veneto Anziani) study. Clin Exp Rheumatol. 2009; 27: 981-4.

9. Musacchio E, Ramonda R, Perissinotto E, Sartori L, Hirsch R, Punzi L, et al. The impact of knee and hip chondrocalcinosis on disability in older people: The ProVA Study from northeastern Italy. Ann Rheum Dis. 2011; 70: 1937-43.

10. Roudy E, Doherty M. Epidemiology of gout. Arthritis Res Ther. 2010; 12: 223.

11. Smith EU, Díaz-Torné C, Perez-Ruiz F, March LM. Epidemiology of gout: an update. Best Pract Res Clin Rheumatol. 2010; 24: 811-27.

12. Becker MA, Schumacher HR, Benjamin KL, Gorevic P, Greenwald M, Fessel J, et al. Quality of life and disability in patients with treatment-failure gout. J Rheumatol. 2009; 36: 1041-8.

13. Lottmann K, Chen X, Schadlich PK. Association between gout and all-cause as well as cardiovascular mortality: a systematic review. Curr Rheumatol Rep. 2012; 14: 195-203.

14. Pillinger MH, Goldfarb DS, Keenan RT. Gout and its comorbidities. Bull NYU Hosp Jt Dis. 2010; 68: 199-203.

15. Khanna PP, Perez-Ruiz F, Maranian P, Khanna D. Long-term therapy for chronic gout results in clinically important improvements in the health-related quality of life: short form-36 is responsive to change in chronic gout. Rheumatology (Oxford). 2011; 50: 740-5.

16. Manara M, Bortoluzzi A, Favero M, Prevete I, Scirè CA, et al. Italian Society of Rheumatology recommendations for the management of gout. Reumatismo. 2013 28; 65: 4-21.

17. Richette P, Bardin T. Gout. Lancet 2010. 23; 375: 318-28.

18. Oliviero F, Scanu A, Galozzi P, Gava A, Frallonardo P, Ramonda R, et al. Prevalence of calcium pyrophosphate and monosodium urate crystals in synovial fluid of patients with previously diagnosed joint diseases. Joint Bone Spine. 2013; 80:287-90.

19. Krishnan E, Tugwell P, Fries JF. Percentile benchmarks in patients with rheumatoid arthritis: Health Assessment Questionnaire as a quality indicator (QI). Arthritis Res Ther. 2004; 6: 505-13.

20. Singh JA, Sarkin A, Shieh M, Khanna D, Terkeltaub R, Lee SJ, et al. Health care utilization in patients with gout. Semin Arthritis Rheum. 2011; 40: 501-11.

21. Ramonda R, Musacchio E, Campana C, Frigato $\mathrm{M}$, Frallonardo $\mathrm{P}$, Barbieri V, et al. Immunogenetic aspects of erosive osteoarthritis of the hand in patients from northern Italy. Scand J Rheumatol. 2011; 40: 139-44.

22. Adenwalla HN, O'Connor CR. Catastrophic axial gout causing paraplegia in a patient with glycogen storage disease. J Clin Rheumatol. 2011; 17: 387-8.

23. Rodríguez Leal CM, Almodóvar R, Zarco P, Mazzuchelli R, Quirós FJ. Intrabony tibial tophi in chronic gout. Reumatol Clin. 2012; 8: 294-7.

24. Punzi L, Oliviero F, Ramonda R. New horizons in osteoarthritis. Swiss Medical Weekly. 2010; 140: 16-22. 
25. Nalbant S, Martinez JA, Kitumnuaypong T, Clayburne G, Sieck M, Schumacher HR Jr. Synovial fluid features and their relations to osteoarthritis severity: new findings from sequential studies. Osteoarthritis Cartilage. 2003; 11: 50-4.

26. Punzi L, Oliviero F, Ramonda R, Valvason C, Sfriso P, Todesco S. Laboratory investigations in osteoarthritis. Aging Clin Exp Res. 2003; 15: 373-9.

27. Punzi L, Oliviero F, Ramonda R. Transforming growth factor- $\beta$ levels in synovial fluid of osteoarthritis with or without calcium pyrophosphate dihydrate crystals. J Rheumatol. 2003; 30: 420-1.

28. Gerster JC, Varisco PA, Kern J, Dudler J, So AK. CPPD crystal deposition disease in patients with rheumatoid arthritis. Clin Rheumatol. 2006; 25: 468-9.

29. Doherty M, Dieppe P, Watt I. Low incidence of calcium pyrophosphate dihydrate crystal deposition in rheumatoid arthritis, with modification of radiographic features in coexistent disease. Arthritis Rheum. 1984; 27: 1002-9.

30. Fuerst M, Bertrand J, Lammers L, Dreier R, Echtermeyer F, Nitschke Y, et al. Calcification of articular cartilage in human osteoarthritis. Arthritis Rheum. 2009; 60: 2694-703.

31. Scanu A, Oliviero F, Ramonda R, Frallonardo P, Dayer JM, Punzi L. Cytokine levels in human synovial fluid during the different stages of acute gout: role of transforming growth factor $\beta 1$ in the resolution phase. Ann Rheum Dis. 2012; 71: 621-4.

32. Dalbeth N, Haskard DO. Mechanisms of inflammation in gout. Rheumatology. 2005; 44: 1090-6.

33. Horowitz MD, Abbey L, Sirota DK, Spiera H. Intraarticular noninflammatory free urate suspension (urate milk) in 3 patients with painful joints. J Rheumatol. 1990; 17: 712-4.

34. Hoffmeister C, Trevisan G, Rossato MF, de Oliveira SM, Gomez MV, Ferreira J. Role of TRPV1 in nociception and edema induced by monosodium urate crystals in rats. Pain. 2011; 152: $1777-88$.

35. Hoffmeister C, Silva MA, Rossato MF, Trevisan G, Oliveira SM, Guerra GP, et al. Participation of the TRPV1 receptor in the development of acute gout attacks. Rheumatology (Oxford). 2013. [Epub ahead of print].

36. Kobayashi K, Fukuoka T, Obata K, Yamanaka H, Dai Y, Tokunaga A, et al. Distinct expression of TRPM8, TRPA1, and TRPV1 mRNAs in rat primary afferent neurons with adelta/cfibers and colocalization with trk receptors. J Comp Neurol. 2005; 493: 596-606.

37. Gentle MJ. Sodium urate arthritis: effects on the sensory properties of articular afferents in the chicken. Pain. 1997; 70: 245-51.

38. Trevisan G, Hoffmeister C, Rossato MF, Oliveira SM, Silva MA, Ineu RP, et al. Transient receptor potential ankyrin 1 receptor stimulation by hydrogen peroxide is critical to trigger pain during monosodium urate-induced inflammation in rodents. Arthritis Rheum. 2013; 65: 2984-95.

39. Schwartz ES, Christianson JA, Chen X, La JH, Davis BM, et al. Synergistic role of TRPV1 and TRPA1 in pancreatic pain and inflammation. Gastroenterology. 2011; 140: 1283-91.

40. Salas MM, Hargreaves KM, Akopian AN. TRPA1-mediated responses in trigeminal sensory neurons: interaction between TRPA 1 and TRPV1. Eur J Neurosci. 2009; 29: 1568-78.

41. Miyamoto T, Dubin AE, Petrus MJ, Patapoutian A. TRPV1 and TRPA1 mediate peripheral nitric oxide-induced nociception in mice. PLoS One. 2009; 29: 7596.

42. Kawabata A. Prostaglandin E2 and pain an update. Biol Pharm Bull. 2011; 34: 1170-3.

43. Pouliot M, James MJ, McColl SR, Naccache $\mathrm{PH}$, Cleland LG. Monosodium urate microcrystals induce cyclooxygenase- 2 in human monocytes. Blood. 1998; 91: 1769-76.

44. Angel J, Audubert F, Bismuth G, Fournier C. IL-1 beta amplifies bradykinin-induced prostaglandin E2 production via a phospholipase D-linked mechanism. J Immunol. 1994; 152: 5032-40.

45. Petho G, Reeh PW. Sensory and signaling mechanisms of bradykinin, eicosanoids, platelet-activating factor, and nitric oxide in peripheral nociceptors. Physiol Rev. 2012; 92: 1699-775.

46. Ginsberg MH, Jaques B, Cochrane CG, Griffin JH. Urate crystal-dependent cleavage of Hageman factor in human plasma and synovial fluid. J Lab Clin Med. 1980; 95: 497506.

47. Swift JQ, Garry MG, Roszkowski MT, Hargreaves KM. Effect of flurbiprofen on tissue levels of immunoreactive bradykinin and acute postoperative pain. J Oral Maxillofac Surg. 1993; 51: 112-6.

48. Ferreira J, Campos MM, Araújo R, Bader M, Pesquero JB, Calixto JB. The use of kinin B1 and $\mathrm{B} 2$ receptor knockout mice and selective antagonists to characterize the nociceptive responses caused by kinins at the spinal level. Neuropharmacology. 2002; 43: 1188-97.

49. Shaw OM, Harper JL. Bradykinin receptor 2 extends inflammatory cell recruitment in a model of acute gouty arthritis. Biochem Biophys Res Commun. 2011; 416: 266-9.

50. Lotz M, Vaughan JH, Carson DA. Effect of neuropeptides on production of inflammatory cytokines by human monocytes. Science. 1988; 241: 1218-21.

51. Sakai K, Matsuno H, Tsuji H, Tohyama M. Substance P receptor (NK1) gene expression in synovial tissue in rheumatoid arthritis and osteoarthritis. Scand J Rheumatol. 1998; 27: 135-41. 
52. Westermark T, Rantapää-Dahlqvist S, Wållberg-Jonsson S, Kjörell U, Forsgren S. Increased content of bombesin/GRP in human synovial fluid in early arthritis: different pattern compared with substance P. Clin Exp Rheumatol. 2001; 19: 715-20.

53. Lunam CA, Gentle MJ. Substance P immunoreactive nerve fibres in the domestic chick ankle joint before and after acute urate arthritis. Neurosci Lett. 2004; 354: 87-90.

54. Martinon F, Pétrilli V, Mayor A, Tardivel A, Tschopp J. Gout-associated uric acid crystals activate the NALP3 inflammasome. Nature. 2006; 440: 237-41.

55. Safieh-Garabedian B, Poole S, Allchorne A, Winter J, Woolf CJ. Contribution of interleukin-1 beta to the inflammation-induced increase in nerve growth factor levels and inflammatory hyperalgesia. Br J Pharmacol. 1995; 115: 1265-75.

56. Inoue A, Ikoma K, Morioka N, Kumagai K, Hashimoto T, Hide I, et al. Interleukin-1beta induces substance $\mathrm{P}$ release from primary afferent neurons through the cyclooxygenase-2 system. J Neurochem. 1999; 73: 2206-13.

57. Samad TA, Moore KA, Sapirstein A, Billet S, Allchorne A, Poole S, et al. Interleukin-1betamediated induction of Cox-2 in the CNS contributes to inflammatory pain hypersensitivity. Nature. 2001; 410: 471-5.

58. Economides AN, Carpenter LR, Rudge JS, Wong V, Koehler-Stec EM, et al. Cytokine traps: multi-component, high-affinity blockers of cytokine action. Nat Med. 2003; 9: 47-52.
59. Kawasaki Y, Xu ZZ, Wang X, Park JY, Zhuang $\mathrm{ZY}$, Tan PH, et al. Distinct roles of matrix metalloproteases in the early- and late-phase development of neuropathic pain. Nat Med. 2008; 14: 331-6.

60. Obreja O, Rathee PK, Lips KS, Distler C, Kress M. IL-1 beta potentiates heat-activated currents in rat sensory neurons: involvement of IL-1RI, tyrosine kinase, and protein kinase C. FASEB J. 2002; 16: 1497-503.

61. Wang ZJ, Snell LD, Tabakoff B, Levinson SR. Inhibition of neuronal $\mathrm{Na}+$ channels by the novel antiepileptic compound DCUKA: identification of the diphenylureido moiety as an inactivation modifier. Exp Neurol. 2002; 178: 129-38.

62. Viviani B, Bartesaghi S, Gardoni F, Vezzani A, Behrens MM, Bartfai T, et al. Interleukin1beta enhances NMDA receptor-mediated intracellular calcium increase through activation of the Src family of kinases. J Neurosci. 2003; 23: 8692-700.

63. So A, De Smedt T, Revaz S, Tschopp J. A pilot study of IL-1 inhibition by anakinra in acute gout. Arthritis Res Ther. 2007; 9: 28.

64. Torres R, Macdonald L, Croll SD, Reinhardt J, Dore A, Stevens S, et al. Hyperalgesia, synovitis and multiple biomarkers of inflammation are suppressed by interleukin 1 inhibition in a novel animal model of gouty arthritis. Ann Rheum Dis. 2009; 68: 1602-8.

65. Moltó A, Ea HK, Richette P, Bardin T, Lioté F. Efficacy of anakinra for refractory acute calcium pyrophosphate crystal arthritis. Joint Bone Spine. 2012; 79: 621-3. 